\title{
Regulação contemporânea de preços de medicamentos no Brasil - uma análise crítica
}

\author{
Contemporary regulation of drug prices in Brazil - a critical analysis

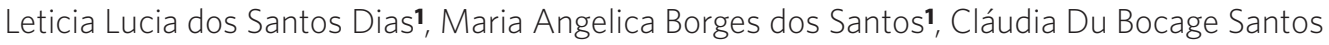 \\ Pinto ${ }^{2}$
}

DOI: $10.1590 / 0103-1104201912120$

RESUMO A regulação de preços visa garantir sustentabilidade à assistência farmacêutica. Com o objetivo de discutir criticamente o tema, elaborou-se um ensaio sustentado em análise documental (2000-2017) da regulação econômica da indústria farmacêutica brasileira na Câmara de Regulação de Medicamentos (CMED), periódicos, teses e publicações do Legislativo e indústria farmacêutica. Vigorando há 15 anos, a Lei n ${ }^{\circ}$ 10.742/2003 instituiu um modelo de teto de preços, compreendendo estabelecimento de preços máximos para medicamentos e reajustes anuais por fórmula definida em lei. Modelo, implementação e fórmula são alvos de crítica. A fórmula vincula reajustes ao Índice Nacional de Preços ao Consumidor Amplo - IPCA (inflação), agregando índices de custos de produção, concorrência e produtividade setoriais. A longevidade do modelo, sem realinhamento periódico dos tetos aos preços de mercado recomendado na literatura especializada, tem gerado preços máximos descolados da realidade, que aumentam a assimetria de informação e podem respaldar futuros aumentos abusivos. A priorização da eficiência do mercado em detrimento do combate à assimetria de informações no modelo regulatório tem reduzido a força dos consumidores no debate. $\mathrm{O}$ atual modelo avançou em relação às políticas de preços liberados, mas seu aperfeiçoamento pressupõe a apropriação do tema e crescente participação de consumidores e profissionais de saúde no processo regulatório.

PALAVRAS-CHAVE Preço de medicamento. Regulamentação governamental. Indústria farmacêutica.

1Fundação Oswaldo Cruz (Fiocruz), Escola Nacional de Saúde Pública Sergio Arouca (Ensp) - Rio de Janeiro (RJ), Brasil. leticialsdias@gmail.com

2 Universidade Federal de Mato Grosso do Sul (UFMGS), Instituto Integrado de Saúde (Inisa) - Campo Grande (MS), Brasil.
ABSTRACT Price regulation aims to ensure sustainability of pharmaceutical care. Aiming to critically discuss the regulation of pharmaceutical prices in Brazil, we elaborated an essay based on document analysis (2000-2017) of the pharmaceutical economic regulation found at the Medication Regulation Chamber (CMED), journals, theses, and publications of the Legislature and pharmaceutical industry. For 15 years, Act no. 10.742/2003 has established a price ceiling model, comprising maximum prices for medicines and annual readjustments according to a formula defined in law. Model, implementation and formula have all been criticized. The formula links adjustments to the IPCA (general inflation index), adding indexes for production costs, competition, and productivity. The longevity of the model, without regular realignment of the ceiling to actual market prices, as recommended in specialized literature, generates price ceilings detached from reality, which deepen information asymmetries and may support abusive price increases in the future. Prioritization of market efficiency over reduction of information asymmetry in the 
regulatory model has reduced the strength of consumers in the debate. The current regulatory model has advanced in relation to previous liberalized pricing policies, but further improvement depends on the appropriation of the theme and increasing participation of consumers and health professionals in the regulatory process.

KEYWORDS Drug price. Government regulation. Drug industry.

\section{Introdução}

Entre 2000 e 2013, os medicamentos foram responsáveis por $19 \%$ a $22,4 \%$ das despesas com saúde no Brasil. Pagamentos diretos do bolso feitos pelas famílias financiaram mais de $80 \%$ desses gastos ${ }^{1}$, sendo a população de menor renda proporcionalmente mais onerada $^{2}$. Essa realidade contrasta com a de países da Organização para a Cooperação e Desenvolvimento Econômico (OCDE), onde os governos financiam mais de $60 \%$ dos medicamentos ${ }^{3}$.

Preços elevados são considerados grandes obstáculos ao acesso a medicamentos, independentemente do grau de desenvolvimento do País ${ }^{3}$. Nesse sentido, há um consenso de que a regulação e o controle de preços dos medicamentos são dimensões-chave para a sustentabilidade dos sistemas de saúde ${ }^{4}$.

Nos últimos 50 anos, o Brasil adotou diversos modelos de controle de preços de medicamentos $^{5}$. Entre 1968 e 1990, vigia um controle direto efetuado pelo extinto Conselho Interministerial de Preços (CIP), órgão do Ministério da Fazenda. Os planos Collor I e II instituíram, entre 1990 e 1992, o controle direto de preços. Do final da era Collor até 2000, os preços foram liberados, passando a ser apenas acompanhados por órgãos governamentais. Na prática, entre 1980 e 2001, os preços tiveram aumentos de $89 \%$ relativamente ao valor do dólar, e de $541 \%$ na correção pela inflação (Bônus do Tesouro Nacional). Um aumento de $267 \%$ ocorreu entre 1987 e
20006. É compreensível, portanto, que um dos destaques na Comissão Parlamentar de Inquérito (CPI) sobre medicamentos, em meados de $2000^{7}$ tenha sido as críticas aos 'aumentos abusivos' nos preços desses produtos. A CPI culminou na implantação, a partir de 2003, de um marco regulatório econômico para o mercado farmacêutico, que permanece essencialmente inalterado até os dias atuais.

Por definição, um mercado sob regulação econômica é aquele que pode sofrer intervenções do Estado ${ }^{8}$. A regulação pressupõe participação ativa das várias partes interessadas para equilibrar riscos e benefícios para todas. Interessados incluem produtores, importadores, cadeia de distribuição, consumidores, financiadores e profissionais de saúde, que atuam como consumidores indiretos ao influenciarem a escolha dos produtos por meio das prescrições?.

Destarte, o presente ensaio pretende apresentar e discutir as regras aplicadas a preços do setor farmacêutico no Brasil, analisando fundamentos técnicos, contexto de implementação e implicações. Argumenta que, ainda que essa regulação tenha promovido avanços comparativamente aos cenários pré-CPI, desestimulou a participação de atores interessados no debate, por sua formulação excessivamente economicista, e promoveu distorções indesejáveis no mercado de medicamentos. Até o momento, configura uma política de precificação alinhada a interesses da indústria farmacêutica, mas nem sempre favorável 
a princípios de funcionamento ótimo do mercado na perspectiva de consumidores e financiadores, principalmente em face do predomínio do financiamento direto do bolso pelas famílias.

O ensaio parte de uma revisão crítica de legislação, normas e documentos técnicos no sítio institucional da Agência Nacional de Vigilância Sanitária (Anvisa) dos anos 2000 até 2017. A análise crítica, que não pretendeu ser exaustiva, é fundamentada em artigos de periódicos nacionais e internacionais, teses e dissertações acessados via Pubmed e Google Scholar, além de publicações técnicas de órgãos do Legislativo e associações da indústria farmacêutica em sítios eletrônicos institucionais, acrescentando-se considerações sobre o contexto brasileiro de financiamento de medicamentos.

A argumentação é desenvolvida em três seções. Na primeira, são apresentados os referenciais teóricos do estudo e aspectos básicos da dinâmica de ajustes de preços na economia, com destaque para o setor farmacêutico. A segunda seção é dedicada às regras para precificação de medicamentos no Brasil desde 2000 e respectivas fórmulas, premissas e críticas. A última seção traz uma análise do contexto de implementação e implicações da regulação, desenvolvendo as teses centrais deste ensaio e reflexões que poderiam informar uma eventual reformulação de nosso marco regulatório.

\section{Preços na economia e na indústria farmacêutica}

Preços espelham uma relação entre oferta e demanda por produtos de distintas naturezas. A disposição dos consumidores para pagar depende do valor atribuído aos produtos, inclusive serem percebidos como essenciais e sua disponibilidade ou escassez no mercado.

Os preços, em nível microeconômico, dependem da quantidade de ofertantes (concorrência/concentração do mercado) e tendem a permanecer vários meses sem modificação (price stickiness) ${ }^{10}$. Reajustes de preços podem ocorrer com a passagem do tempo (time dependent) ou em função de mudanças nas condições da economia (state dependent). No primeiro caso, as mudanças independem de motivações explicitamente econômicas, sendo exógenas à economia, podendo ocorrer com regularidade temporal definida ou aleatoriamente ${ }^{11}$. No segundo caso, as empresas ajustam seus preços segundo mudanças em seus custos ou no cenário econômico.

A indústria farmacêutica é tradicionalmente considerada uma indústria de preços diferenciados por ser baseada em inovação e pesquisa ${ }^{12}$. Os monopólios criados pelas patentes concedidas a produtos inovadores reforçam a prática de preços elevados e uma alta lucratividade ${ }^{13}$. Como dificilmente é possível adiar o uso de um medicamento, a natural retração do consumo verificada quando os preços aumentam é bem menor do que para produtos considerados não essenciais, configurando o que a economia caracteriza como baixa elasticidade-preço ${ }^{14}$.

Dadas a singularidade da dinâmica de mercado e a essencialidade de seus produtos, a indústria farmacêutica tem seus preços regulados na maior parte dos países. Onde há fornecimento público de medicamentos, a regulação de preços, além de proteger o consumidor, tenta reduzir o impacto de gastos com medicamentos sobre as contas públicas.

No que tange à dinâmica de precificação, os preços de qualquer medicamento oscilam segundo interações entre oferta e demanda. Produtores e distribuidores (oferta), por um lado, definem limites mínimos aceitáveis de preços com base em custos de produção e retorno esperado sobre o investimento realizado. O mercado consumidor, por outro lado, atribui um valor ao produto e define aquilo que se dispõe a pagar, idealmente no contexto de um ambiente competitivo, no 
qual haja possibilidade de escolher e optar por produtos ou marcas diferentes ${ }^{15}$.

Nesse contexto, informação clara sobre a efetividade dos medicamentos aos prescritores e sobre os preços deles ao consumidor é um pilar central da regulação. A inexistência de referências confiáveis sobre efetividade, preços e possibilidades de substituição dos medicamentos cria um ambiente de 'assimetria de informação', que prejudica o equilíbrio de mercado ${ }^{15}$.

Ao propor um preço para seu produto, a empresa farmacêutica já terá investigado a disposição dos consumidores de pagarem pelo produto e investido em estratégias para majorar essa percepção de valor, como ações de marketing com os médicos. O preço proposto ficará entre o maior valor possível acima do menor retorno do investimento admitido pela empresa e o máximo suportável pelo consumidor ${ }^{15}$. Nesse sentido, os preços podem flutuar em uma faixa, em geral, bastante ampla, em que custos de produção tendem a ser uma variável de baixa relevância frente ao 'valor' atribuído ao produto.

A regulação, portanto, deve buscar promover equilíbrio entre lucros aceitáveis para a indústria e preços acessíveis para consumidores e financiadores. Isso envolve a modulação da capacidade das empresas de impor preços (força de mercado) e a redução da assimetria de informação, no sentido de possibilitar escolhas informadas por parte dos consumidores/prescritores em aspectos relativos a preço e benefícios dos medicamentos (custo-benefício).

Os regimes de financiamento de medicamentos são muito relevantes para nortear as diretrizes regulatórias. Em mercados nos quais predomine o financiamento público de medicamentos, o polo consumidor, representado pelo governo, tende a ter mais poder de barganha do que naqueles em que predominem consumidores isolados pagando diretamente, caso do Brasil.

\section{Regras contemporâneas para precificação de medicamentos no Brasil}

Como desdobramento da CPI de 2000, ficou definida a necessidade de reduzir a escalada de preços de medicamentos e realinhá-los a patamares da década anterior. Duas medidas foram tomadas. A primeira foi a desoneração da tributação dos medicamentos pelo PIS/Cofins (Programa de Integração Social/Contribuição para Financiamento da Seguridade), que reduziu imediatamente os preços em $10 \%$ e transformou o Imposto sobre Operações relativas à Circulação de Mercadorias e Prestação de Serviços de Transporte Interestadual e Intermunicipal e de Comunicação (ICMS) no principal imposto sobre medicamentos no País. A segunda compreendeu estabelecer legislação ${ }^{16,17}$ para desindexar os preços de medicamentos de índices de correção pela inflação. A Lei $n^{0} 10.213 / 2001$ tinha vigência restrita a 2001 e criava a Câmara de Medicamentos (Camed), encarregada de definir reajustes e acompanhar o mercado. O teto anual para Reajuste Médio de Preços (RMP) seria baseado na Evolução Média de Preços (EMP) e em um Índice Paramétrico de Medicamentos (IPM), definido pelo Grupo de Trabalho de Regulação do Setor Farmacêutico ${ }^{16}$.

Nesse primeiro momento, o Grupo de Trabalho optou por um modelo de regulação baseado no controle de lucros das empresas. Esse modelo previa a recomposição de custos setoriais - inclusive variações nos custos de matéria-prima nacional e importada, mão de obra e amostra grátis - acrescida de uma margem fixa de lucro líquido (quadro1) ${ }^{\mathbf{1 8}}$. O IPM para 2001 foi fixado em 4,4\%, bem abaixo da inflação (Índice Nacional de Preços ao Consumidor Amplo - IPCA) de 7,67\%.

Essa primeira lei foi substituída pela Lei $\mathrm{n}^{\mathrm{o}} 10.742 / 2003^{19}$, com por prazo de validade indeterminado e com duas alterações fundamentais em relação à anterior. 
Quadro 1. Pesos e parâmetros dos componentes no preço final de medicamentos em 2002

\begin{tabular}{lll}
\hline Item & Peso (2002) & Parâmetro \\
\hline $\begin{array}{l}\text { Índice de correção matérias-primas } \\
\text { importadas }\end{array}$ & $29,02 \%$ & $\begin{array}{l}\text { Cesta de moedas composta pelo dólar (50\%), marco } \\
\text { alemão (15\%) e franco suíço (35\%) }\end{array}$ \\
Matérias-primas locais & $4,34 \%$ & IPCA geral \\
Mão de obra & $4,30 \%$ & IPCA geral \\
Outros custos & $6,54 \%$ & IPA industrial \\
Despesa de pessoal & $8,61 \%$ & IPCA geral \\
Outras despesas & $23,34 \%$ & IPCA geral \\
Amostra grátis & $5,55 \%$ & - \\
Lucro líquido & $18,30 \%$ & - \\
\hline
\end{tabular}

Fonte: Elaboração própria a partir de informações obtidas junto ao Grupo de Trabalho de Regulação do Setor Farmacêutico, com participação do setor regulado 16 .

A Camed seria substituída pela Câmara de Regulação do Mercado de Medicamentos (CMED), com as atribuições de: a) autorizar preços de entrada para medicamentos novos no mercado brasileiro; e b) acompanhar o mercado e autorizar reajustes de preços para medicamentos já comercializados, nos limites permitidos pela Lei ${ }^{19}$.

A atuação da regulação do setor farmacêutico passava a pautar-se em um modelo de teto de preços, regido por mecanismos que estimulem a oferta de medicamentos e a competitividade do setor ${ }^{19}$. A estratégia regulatória previa aumentar a concorrência no setor farmacêutico para reduzir a concentração e a capacidade das empresas de imporem preços (força de mercado). Nesse sentido, criava incentivos à introdução de novos produtos - fossem eles novas apresentações, formas farmacêuticas, associações de fármacos já existentes ou genéricos - e definia uma fórmula de reajuste de preços em que medicamentos de segmentos com menos concorrência (mercados mais 'concentrados') recebem reajustes menores.

\section{Definição de preço de entrada de medicamentos novos}

O preço base para definir o preço de entrada de medicamentos novos no mercado brasileiro é o Preço de Fábrica (PF). Os medicamentos são classificados segundo critérios de inovação e ganho terapêutico (Categorias I e II), ou como produtos que possam contribuir para aumentar a concorrência no mercado (Categorias III a VI) (quadro 2) 20,21.

Quadro 2. Categorias e critérios para definição de preços de entrada de novos produtos e novas apresentações no mercado brasileiro

\begin{tabular}{|c|c|c|c|}
\hline Categorias & Nível de inovação & Requisitos & Critérios para definição de Preço de Fábrica \\
\hline । & Inovadores & $\begin{array}{l}\text { Com ganhos terapêuticos; } \\
\text { a) Maior eficácia; } \\
\text { b) Mesma eficácia, com menos eventos } \\
\text { adversos; } \\
\text { c) Mesma eficácia, com menor custo total } \\
\text { do tratamento }\end{array}$ & $\begin{array}{l}\text { - PF* não superior ao praticado pelos países de referênciaa para o } \\
\text { mesmo produto, sendo necessária a comercialização em pelo menos } \\
3 \text { dos países; } \\
\text { - Produto não comercializado em pelo menos } 3 \text { países de referência: } \\
\text { definição de preço provisório revisto a cada } 6 \text { meses. }\end{array}$ \\
\hline
\end{tabular}


Quadro 2. (cont.)

Inovadores

Sem ganhos terapêuticos

III

Novas apresenta- Medicamento já comercializado pelo ções

fabricante

IV

Novas apresenta-

ções

Medicamento NÃO comercializado pelo fabricante

Novas formas farmacêuticas

Medicamento já comercializada pelo fabricante

Novas associações Nova associação de fármacos no Brasi de fármacos

Novas formas farmacêuticas

$\mathrm{VI}$

Medicamentos genéricos
De acordo com a Lei no 9.787, de 10 de fevereiro de 1999
- PF definido segundo custo do tratamento com medicamentos comercializados para a mesma indicação terapêutica - não pode ser superior ao menor preço praticado nos países de referência;

- Se o mesmo produto não for comercializado nos países de referência: preços de produtos com o mesmo princípio ativo serão considerados.

- PF proposto não poderá ultrapassar a média aritmética dos preços das apresentações dos medicamentos comercializados pela empresa com mesma concentração e forma farmacêutica;

- Se o critério acima não for atendido: a média é obtida com base nas apresentações da mesma forma farmacêutica, guardando-se a proporcionalidade direta com a concentração do princípio ativo.

- Preço proposto não deve ultrapassar o preço médio ponderado de apresentações de produtos com os mesmos princípios ativo, concentração e forma farmacêutica já comercializadas;

- Se o critério acima não for atendido: todas as apresentações do mesmo princípio ativo e mesma forma farmacêutica são consideradas no cálculo.

- Preço definido de acordo com custo do tratamento para produtos comercializados para a mesma indicação. O custo não pode ser maior que o menor preço praticado nos países de referência;

- Nova forma farmacêutica com ganho terapêutico: pode-se utilizar a diferença relativa da média dos preços nos países de referência;

- Ganho terapêutico por tecnologia nacional: fabricante pode justificar preço proposto a CMED.

- Preço máximo equivalente a $65 \%$ do preço do medicamento de referência;

- Se nova apresentação de genérico já comercializado: PF não pode ser maior que a média aritmética dos preços das outras apresentações do mesmo genérico, de igual concentração e forma farmacêutica, comercializado pela empresa.

Fonte: Resolução no 2, de 5 de março de 200420

${ }^{\star} \mathrm{PF}=$ Preço de Fábrica.

A partir da classificação de seu produto em uma dessas categorias, o fabricante propõe à CMED um $\mathrm{PF}$ de entrada. No caso de o medicamento não ser comercializado no País, o preço não pode ser superior ao praticado em pelo menos três entre nove países de referência - Austrália, Canadá, Espanha, Estados Unidos da América, França, Grécia, Itália, Nova Zelândia e Portugal20,21. Adicionalmente, para medicamentos inovadores (Categorias I e II), o preço proposto deve basear-se em estudos que demonstrem eficácia e benefícios econômicos. Para medicamentos das demais categorias, os preços de lançamento são referenciados ao mercado interno.
A regulação brasileira vem cumprindo bem seu objetivo de ampliar a quantidade de produtos no mercado. Entre 2013 e 2016, as solicitações para precificação de novas apresentações cresceram 42\%. Apenas em 2016, a CMED analisou propostas para 2.407 novas apresentações, em que predominaram genéricos (Classe VI) (42\%) e novas apresentações de produtos já comercializados pelo fabricante (Classe III) (24\%). Apenas 2\% foram moléculas inovadoras (Classe I)22, existindo ainda a conceitualmente confusa Classe II (produtos inovadores sem ganhos terapêuticos).

O quadro 3 mostra as classificações com precificação pleiteada segundo categoria e a redução média dos preços de entrada após a 
análise pela CMED. Na visão do relatório da CMED, categorias com critérios de análise menos objetivos tendem a ter maiores percentuais de indeferimento e redução média dos preços de entrada ${ }^{22}$. Essa é uma constatação improcedente, já que a Categoria I, na qual as regras de precificação incluem preços internacionais e estudos econômicos, em geral complexos, tem médias de redução nos preços pleiteados pelo fabricante menores do que os genéricos, cujas regras de precificação são as mais objetivas. Isso ocorre, pois a regulação é fundamentalmente desenhada e operada para o benefício da indústria9 .

Quadro 3. Análises de pedidos de precificação de apresentações novas de medicamentos, segundo categoria.

\begin{tabular}{llll}
\hline Categoria & $\begin{array}{l}\text { Quantidade } \\
\text { apresentações }\end{array}$ & $\begin{array}{c}\text { Redução média de preço } \\
\text { de entrada após análise }\end{array}$ \\
\hline I - Inovadores & 47 & 2 & 13,38 \\
II - Inovadores & 119 & 5 & 38,78 \\
III - Novas apresentações & 587 & 24 & 22,79 \\
IV - Novas apresentações/ Novas formas farmacêuticas & 342 & 14 & 21,44 \\
V - Novas associações de fármacos/Novas formas farmacêuticas & 36 & 1 & 19,50 \\
VI - Genéricos & 1011 & 42 & 18,15 \\
Transferência de titularidade & 176 & 4 & 21,77 \\
Outros casos omissos & 89 & 4 & 37,98 \\
\hline
\end{tabular}

Fonte: Anvisa, 2017. Relatório de Atividades da Secretaria Executiva da CMED22

A partir da definição do PF de entrada, são calculados Preço Máximo de venda ao Consumidor (PMC) e Preço Máximo de Venda ao Governo (PMVG), aplicável a uma lista variável de medicamentos que onerem de forma expressiva as compras públicas. $\mathrm{O}$ PMVG implica a aplicação de um desconto obrigatório, o Coeficiente de Adequação de Preço (CAP), ao $\mathrm{PMC}^{\mathbf{2 1}, \mathbf{2 3}}$.

\section{Reajuste de preços de medicamentos já comercializados}

Uma vez introduzidos no mercado, os medicamentos passam a ter seus preços máximos reajustados anualmente segundo o modelo teto de preços (price cap) ${ }^{\mathbf{2 4}}$. O fabricante/ fornecedor é livre para alterar seus preços, contanto que não ultrapassem o teto permitido pela regulação ${ }^{25}$. A fórmula de reajuste máximo permitido inclui um índice geral de inflação da economia, sujeito a descontos ou acréscimos que variam em função de níveis de concorrência do segmento de mercado no qual o medicamento se insere.

A fórmula que define a Variação Percentual do Preço (VPP) anual dos medicamentos é apresentada na Lei ${ }^{0} 10.742 / 2003^{26}$ como: $\mathrm{VPP}=\mathrm{IPCA}-\mathrm{X}+\mathrm{Z}^{\mathbf{2 7}, 28}$.

A correção básica pelo IPCA é ajustada segundo os fatores $\mathrm{X}$ (Fator de produtividade da indústria farmacêutica), Y (Fator de ajuste relativo entre setores) e $\mathrm{Z}$ (Fator de ajuste relativo intrassetor).

O Fator $\mathrm{X}^{\mathbf{2 7}, 28}$ busca captar mudanças nas condições de produção dos medicamentos que gerem redução dos custos, o que, em 
tese, deveria traduzir-se em uma redução dos preços no mercado. Esse é o motivo pelo qual aparece como 'deflator' na fórmula.

Ainda que a produtividade do setor farmacêutico não seja uniforme, o Fator $\mathrm{X}$ é um fator único, aplicável a todos os segmentos da indústria farmacêutica (incluindo produtos farmacêuticos e farmoquímicos). É definido com base no Índice de Produtividade do Setor Farmacêutico, que utiliza um modelo econométrico preditivo e considera uma razão entre Índice de Produção Física e total de horas trabalhadas no setor farmacêutico ${ }^{29}$. O Fator de produtividade (X) nunca é negativo, pois, se isso fosse admitido, acrescentaria um valor a mais ao IPCA segundo a fórmula. Quando a previsão de produtividade para a indústria farmacêutica é negativa, o Fator $\mathrm{X}$ assume valor nulo ${ }^{29}$. Na prática, quanto menor a produtividade estimada para o setor, maior o aumento permitido.

O Fator Y incorpora variáveis relevantes no sentido oposto, ou seja, aumentos nos custos de produção da indústria farmacêutica, que precisariam ser compensados. Seu cálculo considera médias anuais de variação de custos com importação de insumos e variação das tarifas públicas (como a taxa de variação real da energia elétrica - definida pela Agência Nacional de Energia Elétrica - Aneel e ajustada pelo IPCA). Quando o Fator Y é negativo, representando queda dos custos de produção, não há subtração deste fator do IPCA, e seu valor permanece zero. Valores negativos do Fator Y são acumulados e descontados em momentos futuros de aumento dos custos de produção (Fator Y positivo) ${ }^{30}$.

Os níveis de concorrência do mercado definem-se segundo o chamado Fator Z. O parâmetro original do texto da lei definia o Fator Z como concentração de mercado segundo participação de genéricos em cada segmento. Quanto mais genéricos, maior a concorrência. Após uma consulta pública realizada em 2014, passou-se a utilizar o Índice de Herfindahl-Hirschman (IHH), um método mais complexo, que analisa os chamados mercados relevantes ${ }^{\mathbf{2 8}}$.

O Fator Z aloca os medicamentos em três níveis de concentração do mercado, atribuindo a eles autorizações de reajuste distintas, referidas a ficarem ou não obrigadas a descontarem o Fator X (figura 1)

Figura 1. Níveis de concentração do mercado

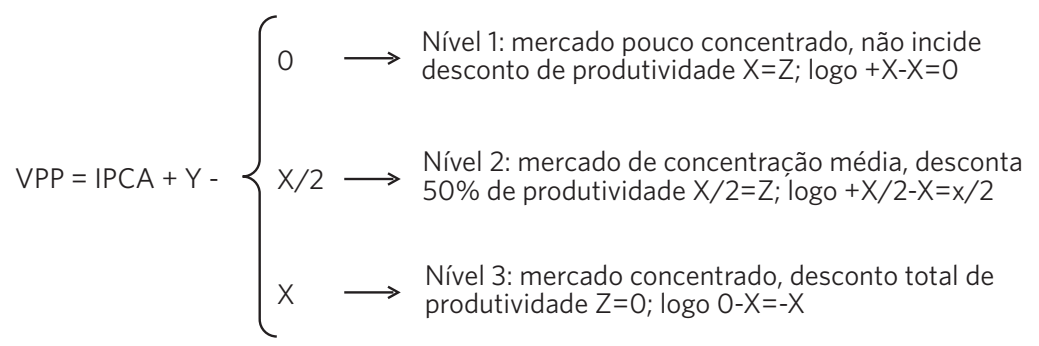

Fonte: Elaboração própria 
A Tabela de Teto de Preços (PF, PMC e PMVG) é atualizada anualmente para cada medicamento, apresentação e marca, em geral, no mês de abril, segundo as várias alíquotas de ICMS estaduais, ficando disponibilizada para consulta do sítio da Anvisa.

\section{Críticas às regras atuais}

Nos últimos anos, muitas foram as críticas feitas ao modelo regulatório de preços de medicamentos, abrangendo desde aspectos gerais do modelo até considerações técnicas pontuais à fórmula adotada 24,31-36.

Uma primeira e importante consideração é a de que os modelos regulatórios baseados em teto de preços, como os adotados no Brasil, pressupõem realinhamentos dos preços aos valores de mercado a cada dois até, no máximo, cinco anos ${ }^{37}$. Sustenta-se, inclusive, que esse modelo seja temporário e aplicável a momentos de transição $0^{35}$. No Brasil, permanece há 15 anos em vigor, sem qualquer realinhamento, com consequentes distorções acumuladas entre preços máximos permitidos e preços praticados.

Alega-se que o modelo de teto de preços traz benefícios ao consumidor ao incentivar as empresas a buscarem reduzir custos, gerando maior eficiência para permitir maiores lucros, o que não seria possível em um modelo baseado em controle de lucros. As hipóteses subjacentes são que uma redução nos custos gere queda de preços ou que a maior produtividade seja captada no Fator X e reverta como benefício aos consumidores. Na prática, reduções de custos não necessariamente acompanham-se de quedas nos preços ${ }^{24}$. Assim, o modelo seria mais indicado para promover eficiência produtiva nas empresas do que para propiciar reduções de preços ${ }^{35}$.

Nesse sentido, Luciana Teixeira acertadamente questiona se o objetivo principal da regulação seria incentivar ganhos de produtividade nas empresas ou garantir preços mais baixos para ampliar o acesso a medicamentos. Há que se considerar, também, que incentivos para reduzir custos podem favorecer práticas que comprometem a qualidade dos produtos sujeitos a controle ${ }^{32}$.

A centralidade conferida à concorrência é outra questão controversa. Estudos mostraram que, para uma lista de mais de uma centena de medicamentos essenciais, inexiste relação entre quantidade de fabricantes e preços $^{38}$. Paradoxalmente, por integrarem mercados em que há mais concorrência, medicamentos essenciais e genéricos comumente usados são os que fazem jus aos maiores reajustes segundo a legislação. Uma fórmula que permite reajustes maiores a setores nos quais as reduções de custos tendem a ser mais acentuadas propicia um descolamento do movimento natural do mercado de redução relativa do preço desses medicamentos ao longo do tempo, que desmoraliza a regulação.

Adicionalmente, o estímulo ao lançamento de novos medicamentos para aumentar a concorrência inunda o mercado com produtos que não agregam valor terapêutico e contribuem para aumentar a 'poluição informacional' para prescritores e consumidores. Essa é uma prática pouco comum em países com financiamento público elevado de medicamentos baseado em critérios claros de reembolso governamental segundo princípio ativo.

A forma de definição dos preços de entrada dos medicamentos pode ser criticada por dois motivos. Primeiro, em mercados em que há controle de preços, diante da incerteza dos patamares de consumo de qualquer medicamento novo, as empresas tendem a propor preços de entrada mais elevados ${ }^{39}$, frustrando os objetivos da regulação. O segundo motivo refere-se à utilização de preços de referência externos ou internacionais ${ }^{40}$. Essa política é adotada principalmente em países de alta renda, que usam como referência países de região geográfica, economias e situação de saúde similares. As referências internacionais brasileiras não preenchem esses critérios, tampouco consideram diferenças de renda e disponibilidade para pagar ${ }^{\mathbf{4 1}}$.

$\mathrm{O}$ uso de preços de referência externos 
por grande número de países tem, ademais, incentivado a indústria farmacêutica a priorizar lançamentos de medicamentos novos em países onde os preços são mais altos ${ }^{\mathbf{4 2}}$, garantindo preços de referência sempre os maiores possíveis e retardando lançamentos em países que pagam menos.

Quanto à fórmula de reajuste anual, todos os fatores foram alvos de crítica. A adoção do IPCA gera correções nos preços teto que são sempre ascendentes, quando, no mercado de medicamentos, pela elevada contribuição da patente no preço inicial, os produtos mais antigos tendem a uma redução gradual de preços ${ }^{31}$. Além disso, o IPCA compõe a fórmula de reajuste de preços em três momentos: no índice de inflação; como variável explicativa do método utilizado para o cálculo do Fator X; e no Fator Y, que incorpora novamente ao cálculo do ajuste, a título de recomposição de custos setoriais, variáveis já contabilizadas no IPCA ${ }^{33}$.

Sobre o Fator X, que representa a produtividade setorial, a literatura fornece pouca orientação. A escolha dos parâmetros corretos para esse Fator é crítica. Se o Fator $\mathrm{X}$ for baixo demais, as empresas auferirão de lucros excessivos, colocando em risco o suporte político ao modelo. Se o Fator X for muito elevado, o modelo será erodido pela falta de adesão das empresas ${ }^{\mathbf{4 3}}$. No caso brasileiro, diferentes formas de cálculo da produtividade podem gerar resultados opostos aos obtidos na $\mathrm{CMED}^{34}$. Alguns autores ainda ressaltam que não está claro o que está sendo medido como produtividade no método adotado, bem como as relações entre a série de produtividade (variável dependente) e taxas de câmbio real/dólar, Produto Interno Bruto (PIB), Taxa Básica de Juros (Selic) e IPCA (variáveis explicativas) $)^{33,34}$.

Outra questão polêmica é o fato de o Fator Y não assumir valores negativos - o que espelharia uma saudável queda dos custos de produção, com potencial contribuição para uma redução paulatina de preços de medicamentos ao longo do tempo. Na regra brasileira, uma queda nos custos de produção (Fator Y negativo) transforma-se em zero e 'acumula-se' para ser descontada em momentos futuros em que passe a ser positiva ${ }^{10}$. Se vários anos sucessivos transcorrerem com queda nos custos de produção, o consumidor deixará de usufruir dos descontos acumulados ao longo desse período. Há também problemas relacionados com a matriz insumo-produto adotada para calcular custos de produção, que não fornece informações no nível de desagregação requerido, tampouco é atualizada regularmente ${ }^{33}$.

Quanto ao Fator Z, que delimita os três níveis de concentração de mercado para fins de reajuste, este está atrelado à definição dos 'mercados relevantes', que pode ser muito variável. Definições de abrangência demasiadamente amplas resultam em subestimação do mercado real, enquanto definições mais reduzidas levam a superestimação do mercado ${ }^{44}$.

\section{$O$ contexto da implementação da regulação}

A análise das políticas brasileiras de regulação contemporâneas deve considerar o contexto de seu surgimento e a conformidade com os modelos regulatórios que as informam. Após a CPI de medicamentos, consolidaram-se iniciativas de controle de preços em que foram adotados em sucessão dois modelos de regulação - controle de lucros, com desindexação dos preços em relação ao IPCA, na Lei $\mathrm{n}^{0} 10.213 / 2001^{16}$; e controle por teto de preços, na Lei ${ }^{\circ} 10.742 / 2003^{26}$, que restabelece a indexação, e prioriza dinâmicas de mercado - produtividade e concorrência setoriais. Não há como avaliar se o primeiro modelo, que foi rapidamente substituído, teria mais sucesso do que o atual.

Também não resta dúvida de que a regulação de preços de medicamentos promoveu avanços comparativamente aos cenários préCPI. Ainda que a CPI tenha recomendado a desindexação, a opção pela indexação ao IPCA 
no modelo regulatório atual se deu em um contexto de aumentos que excediam em muito a inflação, o que já transforma aumentos atrelados à inflação em ganho para o consumidor ${ }^{35}$.

Um ponto a destacar é o fato de a regulação contemporânea estar assentada em Leis específicas. A Lei $n^{\circ} 10.742 / 2003$ explicitamente estabelece não apenas o modelo regulatório, mas também a fórmula de reajuste a ser usada. A lei anterior deixava a definição do IPM a cargo do Grupo de Trabalho de Regulação do Setor Farmacêutico, uma situação semelhante a que temos na regulação da saúde suplemen$\operatorname{tar}^{16,26}$. Nesse sentido, pode-se alegar que a legislação vigente reduz a possibilidade de adoção de parâmetros discricionários, que podem eventualmente voltar-se contra os melhores interesses do consumidor.

Entretanto, a opção por leis específicas engessa a regulação. O Tribunal de Contas da União (TCU), que vem tendo importante papel no apontamento de fragilidades do modelo regulatório, considerou que a Lei $\mathrm{n}^{\circ}$ 10.742/200326 não dá respaldo à CMED para corrigir distorções encontradas no mercado brasileiro, pois implica baixa discricionariedade para rever preços utilizando formas não previstas na lei ${ }^{45}$.

O engessamento, no entanto, é relativo, como fica claro na efemeridade da Lei $\mathrm{n}^{\circ}$ $10.213 / 2001^{16}$, com vigência de apenas um ano. O grande obstáculo parece residir no acesso ao Legislativo para gerar mudanças na lei. Mais do que um processo técnico, a regulação é um processo político ${ }^{9}$, recomendando-se um empoderamento dos consumidores no diálogo com o Legislativo, dominado por lobbies da indústria.

O relatório do Acórdão 3.016/2012 do TCU recomendou ao Ministério da Saúde rever o modelo regulatório previsto na Lei $\mathrm{n}^{\mathrm{o}} 10.742 / 2003^{26}$, de forma a desvincular os reajustes da inflação. Após ser constatado que 86\% dos medicamentos de uma amostra de fármacos com maior faturamento apresentavam preço acima da média internacional, sendo 46\% com maior preço no Brasil, recomendou também a revisão periódica dos preços a partir de critérios como comparação internacional, variação cambial e custos dos diferentes tratamentos ${ }^{31,45}$.

O Acórdão deu margem à consulta pública implementada pela Anvisa entre dezembro de 2014 e janeiro de $2015^{46}$, que culminou na mudança de parâmetros para cálculo do Fator $\mathrm{Z}$, mostrando que algum grau de alteração na forma de cálculo dos parâmetros é viável, ainda que vigore a lei atual. Chamaram atenção não só a exiguidade do prazo para opinar, mas o fato de $70 \%$ das contribuições encaminhadas serem de associações de empresas farmacêuticas. Isso destaca a necessidade de prover condições para ampliar a participação e o nível de informação de consumidores e profissionais de saúde nesse debate.

Uma consideração importante na análise das políticas de regulação de preços de medicamentos é a configuração do mercado consumidor, muito negligenciada na legislação atual. O amplo predomínio do gasto direto do bolso como mecanismo de financiamento fragiliza a constituição de um poder de compra organizado para se contrapor ao poder de ditar preços da indústria farmacêutica. No Brasil, compras governamentais são objeto de regras mais favoráveis do que as compras realizadas diretamente pelo consumidor ${ }^{20}$, mas representam menos de $20 \%$ do faturamento do mercado.

A ampla disponibilidade de informação confiável e transparente sobre preços praticados e efetividade dos medicamentos seria fundamental para reequilibrar o mercado. Um ponto-chave das críticas acadêmicas ${ }^{32,36}$ e de Órgãos de Controle ${ }^{31}$ é justamente o questionamento da eficácia regulatória da Tabela de Tetos de Preços da CMED, que deveria ser referência também para preços ao consumidor. Contudo, o enorme descompasso entre preços efetivamente praticados e os preços-teto da Tabela ${ }^{47}$ é admitido pela própria indústria. Os 'descontos' médios praticados pelas empresas no mercado nacional em relação a preços-teto CMED aumentaram de 34,69\% em 2012 para $41 \%$ em $2016^{47}$. Tetos de preços descolados das referências regulatórias contribuem para 
assimetria de informações e concedem à indústria 'gordura' para aumentar preços de mercado a qualquer tempo.

A exigência de fornecimento de informações sobre volumes e valores de vendas pela indústria farmacêutica integra o modelo regulatório desde 2004, com a definição do Sistema de Acompanhamento do Mercado de Medicamentos (SAMMED/Anvisa) e a obrigatoriedade do envio do Relatório de Comercialização $0^{48}$. Entretanto, enfrentou resistências por parte da indústria. A Resolução CMED n $^{\circ} 2 / 2014^{49}$ instituiu a obrigatoriedade de informações semestrais detalhadas pela indústria farmacêutica por meio eletrônico. A partir de 2015, essas informações passaram a ser usadas não só para monitorar o mercado, mas também para medir concorrência e definir o índice $\mathrm{HH}$ na elaboração do Fator Z. O SAMMED permitiria uma revisão bem informada sobre preços praticados, mas sua potencialidade para este fim permanece inexplorada, pois a informação tem tratamento confidencial e não pode ser divulgada de forma desagregada ${ }^{21}$.

Em 2017, em meio a polêmicas em torno da Tabela da CMED, o órgão emitiu a Orientação Interpretativa $\mathrm{n}^{0} 2 / 2017^{50}$, que esclarece que a Tabela CMED é tão somente uma Tabela de Teto de Preços. A referência para preços de comercialização de medicamentos são os preços divulgados nas publicações especializadas de grande circulação da indústria farmacêutica. A prática de preços superiores aos dessas publicações passa a ser considerada abusiva e infração às normas regulatórias, introduzindo-se na regulação um parâmetro externo à Agência reguladora e produzido pelo próprio setor regulado.

Com isso, o que também se estabelece no mercado de preços de medicamentos é um agravamento das assimetrias de informações. A regulação passa a admitir duas tabelas alternativas de preços máximos uma da Agência Regulatória, com reconhecidas distorções, e outra, elaborada pela própria indústria farmacêutica.
Aparentemente, a indústria farmacêutica não tinha, até recentemente, muitos questionamentos ao modelo regulatório vigente. Com a cronificação da crise econômica no País, começam a crescer clamores como as de que "há 11 anos o reajuste de preços de medicamentos fica abaixo da inflação"51(1). Tais alegações consideram somente os parâmetros de reajustes de preços e desconsideram o lançamento de um número crescente de produtos a preços internacionais no mercado brasileiro, gerando aumento do peso dos medicamentos na cesta de consumo das famílias.

No que diz respeito à posição da indústria farmacêutica, vale a premissa de Cespedes et al.52: em um contexto de inflação positiva e sustentada, típico da maioria das economias, é comum às empresas recorrerem, mais do que a definições de níveis de reajuste, a tentativas de estabelecer uma política atraente de preços. O intuito dessas políticas seria preservar ao máximo uma flexibilidade ascendente de preços, que permita aproveitar oportunidades de mudança e as proteja de eventuais choques econômicos. Idealmente, a indústria define os patamares iniciais de preços e uma taxa incondicional que as possibilite atualizar seus preços futuros - "uma taxa de inflação específica da empresa"52(3).

Considerando a exposição das economias emergentes a choques ${ }^{53}$, as empresas somente concordarão com regras que limitem reajustes de preços se as políticas de reajuste forem consideradas satisfatórias, segundo sua perspectiva 9 . Na década de 1990, incertezas econômicas e altíssimos índices inflacionários favoreceram pressões para desvincular os reajustes de qualquer indicador. Em uma situação de maior estabilidade inflacionária, já perceptível no País por ocasião da CPI de Medicamentos, o teto de preços da CMED criou um 'seguro' inicial dos níveis de preço e uma taxa incondicional para reajustes futuros, baseada na inflação.

Enquanto a inflação e o câmbio permanecerem sob controle, parece interessante para a indústria apostar na indexação dos preços ao 
IPCA e pressionar para acelerar a introdução de novos medicamentos a preços internacionais ou 'novas' formas e apresentações a preços reanalisados pela CMED.

Com o arrastar da crise econômica e, particularmente, com as persistentes altas no câmbio, a indústria volta a manifestar desconforto com o panorama regulatório. Ou seja, em cenários de maior instabilidade econômica, pode-se voltar a ter pressões por mudanças regulatórias partindo da indústria.

No cenário brasileiro, abundam também fatores que contribuem para a assimetria de informações, com uma enorme profusão de comunicados, normas interpretativas e o respaldo oficial a múltiplas tabelas de referência para preços de medicamentos. Acrescente-se a isso o fato de a discussão ser dominada por economistas e advogados e mantida em um nível de tecnicismo que desestimula a participação dos profissionais de saúde. Considerando-se a teoria da regulação e a necessidade de representação de todas as partes interessadas, bem como a capacidade de mobilização de profissionais da saúde pública, é urgente que estes últimos se apropriem dessa temática.

\section{Considerações finais}

O modelo regulatório brasileiro para preços de medicamentos nem sempre é favorável a princípios de funcionamento ótimo do mercado na perspectiva de consumidores e financiadores. A regulação vigente tem como norte reduzir a força de mercado dos produtores e sua capacidade de impor preços pelo aumento da produtividade, eficiência e concorrência da indústria farmacêutica. Embute a premissa de que a simples ampliação da concorrência, sem maiores análises sobre a natureza dessa concorrência ou as características do mercado consumidor e seu financiamento, implique redução de preços.

Ao estimular o lançamento de novos produtos, a regulação acaba por criar oportunidades para situações de 'falsa concorrência', que concorre para agravar a assimetria de informações em um mercado sustentado pelo desembolso direto de uma população com níveis de informação muito baixos. $\mathrm{O}$ crescente descolamento entre preços praticados no mercado e as Tabelas de Tetos de Preços oficiais reduz ainda mais o poder desse consumidor de saber escolher e influenciar preços.

Caberia realinhar periodicamente os tetos de preços à realidade de mercado, em concordância com o recomendado pela literatura para esse modelo regulatório, e garantir maior poder ao consumidor. Nesse sentido, uma medida imediata seria aumentar a transparência dos preços ao consumidor (pacientes e prescritores). Os esforços engendrados pela Anvisa nesse sentido ainda são largamente insuficientes.

\section{Colaboradores}

Dias LLS (0000-0002-8082-7280)*, Borges dos Santos MA (0000-0002-7547-3537)*, Santos Pinto CDB (0000-0002-5478-4977)* contribuíram para idealização do artigo, análise da literatura e normativas, elaboração do artigo e revisão do manuscrito. 


\section{Referências}

1. Instituto Brasileiro de Geografia e Estatística (IBGE). Conta-satélite de saúde: Brasil, 2010-2015. Rio de Janeiro: IBGE; 2017. 71 p.

2. Garcia LP, Sant'Anna AC, Magalhães LCG, et al. Gastos das famílias brasileiras com medicamentos segundo a renda familiar: análise da Pesquisa de Orçamentos Familiares de 2002-2003 e de 2008-2009. Cad. Saúde Pública. 2013; 29(8):1605-16.

3. Belloni A, Morgan D, Paris V. Pharmaceutical expenditure and policies: past trends and future challenges. Paris: OECD; 2016.

4. Organisation for Economic Co-operation and Development. Fiscal Sustainability of Health Systems. Paris: OECD; 2015

5. Romano LAN. Intervenção e Regulação no Brasil: a indústria farmacêutica. São Paulo: Febrafarma;2005.116 p.

6. Follador W. Alguns aspectos da variação de preços de medicamentos no Brasil entre os anos de 1980 e 2001. São Paulo: USP; 2001.

7. Brasil. Câmara dos Deputados. Relatório da CPI-Medicamentos. Brasília, DF: Câmara dos deputados; 2000.

8. Viscusi WK, Harrington JE, Vernon JM. Economics of Regulation and Antitrust. 4. ed. Cambridge: MIT Press; 2005. 960 p.

9. Stigler GJ. The Theory of Economic Regulation. Bell J Econ Manag Sci. 1971; 2(1):3-21.

10. Bils M, Klenow PJ. Some Evidence on the Importance of Sticky Prices. J Polit Econ. 2004; 112(5):947-985.

11. Calvo G. Staggered Prices in a Utility-Maximizing Framework. J Monet Econ. 1983; 12(3):383-398.

12. Backhaus J. Competition, innovation and regulation in the pharmaceutical industry. Manag Decis Econ. 1983; 4(2):107-121.
13. Chaves GC, Hasenclever L, Oliveira MA. Redução de preço de medicamento em situação de monopólio no Sistema Único de Saúde: o caso do Tenofovir. Physis Rev Saúde Coletiva. 2018; 28(1):1-16.

14. World Health Organization (WHO). Pharmaceutical pricing policy. In: Management Sciences for Health. Managing access to medicines and health technologies; 2012. p. 9.2-9.21.

15. Gregson N, Sparrowhawk K, Mauskopf J, et al. Pricing medicines: theory and practice, challenges and opportunities. Nat Rev Drug Discov. 2005; 4(2):12130.

16. Brasil. Presidência da República. Lei ${ }^{\circ} 10.213$, de 27 de março de 2001. Define normas de regulação para o setor de medicamentos, institui a Fórmula Paramétrica de Reajuste de Preços de Medicamentos - FPR, cria a Câmara de Medicamentos e dá outras providências. Diário Oficial da União. 28 Mar 2001.

17. Brasil. Presidência da República. Medida Provisória no 2.138-2, de 28 de dezembro de 2000. Define normas de regulação para o setor de medicamentos, institui a Fórmula Paramétrica de Reajuste de Preços de Medicamentos - FPR, cria a Câmara de Medicamentos e dá outras providências. Diário Oficial da União. 29 Dez 2000.

18. Sood N, De Vries H, Gutierrez I, et al. The effect of regulation on pharmaceutical revenues: Experience in nineteen countries. Health Aff. 2009; 28(1):1-24.

19. Brasil. Presidência da República. Lei no 12.527 , de 18 de novembro de 2011. Regula o acesso a informações previsto no inciso XXXIII do art. $5^{\circ}$, no inciso II do $\subseteq 3^{\circ}$ do art. 37 e no $\subseteq 2^{\circ}$ do art. 216 da Constituição Federal; altera a Lei ${ }^{\circ}$ 8.112, de 11 de dezembro de 1990; revoga a Lei $\mathrm{n}^{\circ} 11.111$, de 5 de maio de 2005, e dispositivos da Lei ${ }^{\circ}$ 8.159, de 8 de janeiro de 1991; e dá outras providências. Diário Oficial da União. 18 Nov 2011.

20. Brasil. Câmara de Regulação de Medicamentos. Re- 
solução no 2, de 5 de março de 2004. Aprova os critérios para definição de preços de produtos novos e novas apresentações de que trata $o$ art. $7^{\circ}$ da Lei $n^{\circ}$ 10.742, de 6 de outubro de 2003. Diário Oficial da União. 5 Maio 2004.

21. Brasil. Câmara de Regulação de Medicamentos. Resolução no 4, de 18 de dezembro de 2006. Dispõe sobre o Coeficiente de Adequação de Preços - CAP, sua aplicação, e altera a Resolução CMED n ${ }^{\circ}$. 2, de 5 de março de 2004. Diário Oficial da União. 12 Mar 2007.

22. Agência Nacional de Vigilância Sanitária. Relatório de Atividades 2016. Brasília, DF: ANVISA; 2017.

23. Brasil. Câmara de Regulação de Medicamentos. Resolução no 3, de 2 de março de 2011. Dispõe sobre o Coeficiente de Adequação de Preços - CAP, a sua aplicação, a nova forma de cálculo devido à mudança de metodologia adotada pela Organização das Nações Unidas - ONU, e sobre o Preço Máximo de Venda ao Governo - PMVG. Diário Oficial da União. 9 Mar 2011.

24. Cabral LMB, Riordan MH. Incentives for Cost Reduction under Price Cap Regulation. In: Price Caps and Incentive Regulation in Telecommunications. Boston, MA: Springer US; 1991. p. 155-165.

25. Jamison M. Price Cap and Revenue Cap Regulation. In: Capehart BL, editor. Encyclopedia of Energy Engineering and Technology. New York: CRC Press; 2007. p. 1245-1251.

26. Brasil. Presidência da República. Lei $n^{\circ} 10.742$, de 6 de outubro de 2003. Define normas de regulação para o setor farmacêutico, cria a Câmara de Regulação do Mercado de Medicamentos - CMED e altera a Lei $\mathrm{n}^{\circ}$ 6.360, de 23 de setembro de 1976, e dá outras providências. Diário Oficial da União. 7 Out 2003.

27. Brasil. Câmara de Regulação de Medicamentos. Resolução no 1, de 27 de fevereiro de 2004. Estabelece os critérios de composição de fatores para o ajuste de preços de medicamentos. Diário Oficial da União. 1 Mar 2004

28. Brasil. Câmara de Regulação de Medicamentos. Re- solução nol, de 25 de fevereiro de 2005. Estabelece os critérios de composição de fatores para o ajuste de preços de medicamentos a ocorrer em 31 de março de 2005. Diário Oficial da União. 28 Fev 2005.

29. Brasil. Ministério da Fazenda. Nota Técnica no 163 de 13 de novembro de 2015; 2016.

30. Brasil. Câmara de Regulação de Medicamentos. Resolução no 1, de 23 de fevereiro de 2015. Estabelece os critérios de composição de fatores para o ajuste de preços de medicamentos. Diário Oficial da União. 4 Mar 2015.

31. Tribunal de Contas da União. Relatório de Auditoria TC 034.197/2011-7. Brasília, DF: TCU; 2011.

32. Campos AZS, Franco MPV. Os efeitos da regulação de preços da CMED sobre as compras públicas de medicamentos do estado de Minas Gerais. Rev Gestão em Sist Saúde. 2017; 3(2):253-264.

33. Alves LB. A regulação de preços de medicamentos: aspectos gerais e críticas à metodologia brasileira de reajustes. Brasília, DF: UNB; 2016.

34. Rocha F, Souza IV. Reajuste de preços na indústria farmacêutica brasileira e o fator X: uma avaliação usando o método de fronteiras estocásticas. Rev Gestão Políticas Públicas. 2011; 1(2):131-149.

35. Teixeira LS. Reajustes de preços administrados no setor da saúde. Brasília, DF: Câmara dos Deputados; 2006.

36. Miziara NM, Coutinho DR. Problemas na política regulatória do mercado de medicamentos. Rev Saude Publica. 2015; 49(35):1-6.

37. Cowan S. Price-Cap Regulation and Inefficiency in Relative Pricing. J Regul Econ. 1997; 12(1):53-70.

38. Nóbrega OT, Marques AR, Araújo ACG, et al. Retail prices of essential drugs in Brazil: an international comparison. Rev Panam Salud Publica. 2007; 22(2):118-123. 
39. Shajarizadeh A, Hollis A. Price-cap Regulation, Uncertainty and the Price Evolution of New Pharmaceuticals. Health Econ. 2015; 24(8):966-977.

40. Kanavos P, Fontrier A-M, Gill J, et al. The Impact of External Reference Pricing within and across Countries. Londres: London School of Economics; 2017.

41. Maniadakis N, Kourlaba G, Shen J, et al. Comprehensive taxonomy and worldwide trends in pharmaceutical policies in relation to country income status. BMC Health Serv Res. 2017; 17(371):1-17.

42. Von der Schulenburg F, Vandoros S, Kanavos P. The effects of drug market regulation on pharmaceutical prices in Europe: overview and evidence from the market of ACE inhibitors. Health Econ Rev. 2011; 1(18):1-8.

43. Bernstein JI, Sappington DEM. How to determine the $\mathrm{X}$ in RPI-X regulation: a user's guide. Telecomm Policy. 2000; 24(1):63-68.

44. Dantas AT, Mendonça PAS. Impactos Concorrenciais da Entrada dos Medicamentos Genéricos no Mercado Farmacêutico Brasileiro de 2003 a 2007. Rev Análise Econômica. 2014; 32(62):101-24.

45. Tribunal de Contas da União. Relatório de Auditoria - Acordão 3016/2012. Brasília, DF: TCU; 2012.

46. Anvisa. CMED. Consulta Pública CMED no 1, de 8 de dezembro de 2014. Proposta de regulamentação que estabelece os critérios de composição de fatores para o ajuste de preços de medicamentos. Brasília, DF: Anvisa; 2014.

47. Brasil. Câmara de Regulação do Mercado de Medicamentos - CMED [internet]. [acesso em 2016 jan 1]. Disponível em: http://portal.anvisa.gov.br/listas-de-precos.
48. Brasil. Câmara de Regulação de Medicamentos. Comunicado no 1, de 4 de março de 2004. Diário Oficial da União. 5 Mar 2004.

49. Brasil. Câmara de Regulação do Mercado de Medicamentos. Resolução no 2, de 12 de março de 2014. Dispõe sobre a forma de definição do Preço Fabricante - PF e do Preço Máximo ao Consumidor - PMC dos medicamentos em31 de março de 2014, estabelece a forma de apresentação do Relatório de Comercialização à Câmara de Regulação do Mercado de Medicamentos - CMED, disciplina a publicidade dos preços dos produtos farmacêuticos e define as margens de comercialização para esses produtos. Diário Oficial da União. 27 Mar 2014.

50. Brasil. Câmara de Regulação de Medicamentos. Orientação Interpretativa no 2, de 21 de julho de 2017. O setor varejista deve respeitar o PMC divulgado em publicações especializadas de grande circulação. Diário Oficial da União. 24 Jul 2017.

51. Sincofarma-Goiás. Há 11 anos, o reajuste no preço dos medicamentos fica abaixo da inflação [internet]. 2017. [acesso em 2018 maio 25]. Disponível em: http://www.sincofarma-go.com.br/noticias/ha-11-anos-o-reajuste-no-preco-dos-medicamentos-fica-abaixo-da-inflacao.

52. Céspedes LF, Kumhof M, Parrado E. Pricing Policies and Inflation Inertia. Chile: Banco Central; 2003.

53. Correa AS, Petrassi MBS, Santos R. Price-Setting Behavior in Brazil: survey evidence. Brasília, DF: Banco Central do Brasil; 2016.

Recebido em 17/11/2018

Aprovado em 18/04/2019

Conflito de interesses: inexistente

Suporte financeiro: Departamento de Economia da Saúde,

Investimento e Desenvolvimento do Ministério da Saúde (Desid/ SE/MS) 